\title{
A ORALIDADE EM PROPOSTAS PEDAGÓGICAS NA EDUCAÇÃO BÁSICA: UMA ANÁLISE DO PROCESSO DE ENSINO
}

\author{
Elaine Cristina Forte-Ferreira ${ }^{*}$ \\ Leiliane Aquino Noronha** \\ Juliana Gurgel Soares ${ }^{* * *}$
}

\begin{abstract}
Resumo: O objetivo desta pesquisa é discutir o espaço que se tem destinado para a modalidade oral em propostas pedagógicas desenvolvidas no contexto da educação básica na rede pública do Estado do Ceará. Para tanto, amparamo-nos, especialmente, em Bakhtin (2006), Marcurschi; Dionisio (2007), Forte-Ferreira (2014), Bueno; Costa-Hubes (2015) e em Araújo; Silva (2016). Assim, como corpus, analisamos doze projetos científicos apresentados na VIII Feira Regional de Ciências e Cultura - Ceará científico. Os resultados apontaram uma carência no tocante à abordagem da modalidade oral em sala de aula, demonstrando uma supremacia da escrita. Além disso, um equívoco nas atividades destinadas para o trabalho com a oralidade, já que estas se apresentaram em sua maioria como uma prática de oralização da escrita.
\end{abstract}

Palavras-chave: Oralidade. Propostas pedagógicas. Educação Básica.

\begin{abstract}
This research aims to discuss the space designed to oral modality in pedagogical propositions developed on the context of basic public education in the state of Ceará. The study is based on some authors, especially Bakhtin (2006), Marcuschi; Dionisio (2007), Forte-Ferreira (2014), Bueno; Costa-Hubes (2015) and Araújo; Silva (2016). That being said, the corpus is formed by the analysis of twelve scientific projects presented in the eighth edition of the Cultural and Scientific Regional Fair (VIII Feira Regional de Ciências e Cultura Ceará científico). Results show that there is lack of oral modality concerning the language approaches in classrooms. This situation demonstrates a writing supremacy and causes a misconception towards orality activities since they are seen as practices of reading texts in most of occasions.
\end{abstract}

Keywords: Orality. Pedagogical propositions. Basic Education.

\section{INTRODUÇÃO}

É visto que a língua oral não vem ocupando um lugar relevante em muitas teorias e metodologias situadas no contexto escolar brasileiro, seja através de diversas pesquisas realizadas na área do ensino de línguas ou na observação de algumas práticas cotidianas em sala de aula, bem como em diversos outros materiais didáticos.

Por muitos anos, as discussões sobre a questão estiveram praticamente ausentes do âmbito teórico-metodológico em que se situam os objetos de ensino referentes às experiências com a Língua Portuguesa. Todavia, essa ausência tácita, segundo Araújo e Silva (2016), vem

\footnotetext{
* Docente dos cursos de Letras da UFERSA e do Programa de Pós-graduação em Ensino - POSENSINO - em associação entre a Universidade do Estado do Rio Grande do Norte (UERN), Universidade Federal Rural do Semi-Árido (UFERSA) e Instituto Federal de Educação, Ciência e Tecnologia (IFRN). Líder do Grupo de Pesquisa Oralidade, Letramentos e Ensino - ORALE. E-mail: elaine.forte@ufersa.edu.br

* * Mestranda do Programa de Pós-Graduação em Ensino - POSENSINO, em associação entre a Universidade do Estado do Rio Grande do Norte - (UERN), Universidade Federal Rural do Semi-Árido - (UFERSA) e Instituto Federal de Educação, Ciência e Tecnologia (IFRN). Integrante do Grupo de Pesquisa Oralidade, Letramentos e Ensino - ORALE E-mail: leiliane.aquino@yahoo.com.br

${ }^{* * *}$ Mestranda do Programa de Pós-Graduação em Ensino - POSENSINO, em associação entre a Universidade do Estado do Rio Grande do Norte - (UERN), Universidade Federal Rural do Semi-Árido - (UFERSA) e Instituto Federal de Educação, Ciência e Tecnologia (IFRN). Integrante do Grupo de Pesquisa Oralidade, Letramentos e Ensino - ORALE E-mail: julianagurgel05@ hotmail.com
} 
sendo inquietada há aproximadamente uma década com a propagação de uma série de estudos direcionados para o assunto.

Mesmo com o surgimento de discussões na área, a língua oral parece estar até agora no segundo plano em muitas situações. Ainda que não se negue o avanço das investigações, curiosamente não se pode ocultar também, que mesmo assim, é possível constar uma disparidade quantitativa quando se trata de investigações sobre a modalidade escrita e a modalidade oral da língua (BUENO; COSTA-HUBES, 2015).

$\mathrm{O}$ que se percebe, portanto, é que diante de um meio bastante resistente novos discursos pedagógicos têm começado a integrar gradativamente o contexto escolar e o ensino da modalidade oral, enfatizando, sobretudo a perspectiva do trabalho com os gêneros textuais orais propostos por documentos oficiais, por exemplo, os PCN (BRASIL, 1998). Assim, integramo-nos a essa "invasão de vozes", e embora, o ensino da modalidade oral da língua ainda não ocorra de modo efetivo (TRAVAGLIA, 2013), defendemos aqui a participação ativa dos alunos, seja ela por meio do discurso oral e do escrito.

Nesse sentido, com este artigo propomo-nos a analisar o espaço que se tem destinado para a modalidade oral nos projetos científicos desenvolvidos em turmas da Educação Básica da rede pública do Estado do Ceará. No intuito de atingir o objetivo delineado, discutimos os doze projetos que foram apresentados na realização da VIII Feira Regional de Ciências e Cultura - Ceará científico, uma ação da Coordenadoria Regional de Desenvolvimento da Educação - CREDE $10^{1}$.

Assim sendo, no que diz respeito à organização retórica da nossa discussão, o presente artigo apresenta para além da introdução e considerações (semi) finais, um tópico referente à modalidade oral da língua, assim como destina tópicos para a exposição do percurso metodológico e à análise do corpus explorado.

\section{MODALIDADE ORAL DA LÍNGUA COMO OBJETO DE ESTUDO E DE ENSINO: A NECESSIDADE DE UM TRABALHO EFETIVO}

As acepções relacionadas aos estudos da linguagem e da língua vêm apresentando há muito tempo, através da linguística, diferentes variações e, com isso, inquietando estudiosos nos múltiplos campos de pesquisa numa grande proporção. Busca-se, ao longo do tempo, estabelecer conceitos na tentativa de que ao menos se entenda um dos bens mais preciosos e valorizados por qualquer época, povo e cultura. (MARCUSCHI; DIONISIO, 2007)

Quando falamos, então, em linguagem, entendemos como a capacidade que os seres humanos têm para produzir, desenvolver e compreender a língua, bem como suas outras manifestações (CUNHA; COSTA; MATELOTTA, 2013, p. 16). Por sua vez, em relação ao termo língua, compreendemos como um sistema de práticas sociais e cognitivas, utilizadas pelos falantes/ouvintes para atuarem de forma organizada e efetiva em diferentes contextos. (MARCUSCHI, 2008, p. 61)

Sendo assim, ponderamos que "a linguística tem como objeto de estudo próprio: a capacidade da linguagem, que é observada a partir dos enunciados falados e escritos." (CUNHA; COSTA; MATELOTTA, 2013, p. 20). Apesar disso, diferentemente da atenção dada à língua escrita na linguística, é recente a língua falada como objeto científico (CASTILHO, 2011), assim, muitas foram as mudanças de concepções para que se pudessem considerar as especificidades dessa modalidade.

\footnotetext{
${ }^{1}$ Grupo que atua diretamente com cada escola se responsabilizando pela aplicação da maioria das ações desenvolvidas pela Secretaria de Educação do Estado do Ceará (SEDUC), portanto, o grupo age diretamente com os professores, coordenadores e demais membros em atividade nas unidades de ensino.
} 
Tomando como referência alguns marcos que demonstram o processo de evolução acerca dos estudos linguísticos e também da língua oral, podemos destacar, por exemplo, a visão estruturalista da linguística. Saussure, o pioneiro do estruturalismo estabeleceu - língua e fala - como uma de suas variadas dicotomias. Aqui os termos linguagem e língua são apresentados de forma distinta à concepção citada anteriormente. (CUNHA; COSTA; MATELOTTA, 2013)

Linguagem observada a partir de enunciados falados e/ou escritos só vem ganhar espaço, após propagar, por muito tempo, uma ideia de que esta é notável como um "objeto duplo", ou seja, a linguagem é dividida em um "lado social e individual". Além disso, "língua é um sistema supraindividual utilizado como meio de comunicação entre os membros de uma comunidade." Já a fala constitui "o uso individual do sistema que caracteriza a língua." (CUNHA; COSTA; MATELOTTA, 2013, p. 116) Por consequência, considera-se nesse período somente a parte estrutural/forma da língua.

Sobre essa questão Bakhtin apresenta uma concepção que prioriza "a natureza real dos fatos da língua", pois chama atenção e valoriza "justamente a fala, a enunciação, e afirma sua natureza social, não individual: a fala está indissoluvelmente ligada às condições da comunicação, que, por sua vez, estão sempre ligadas às estruturas sociais." (BAKHTIN, 2006, p. 15) Considerando, então, tais aspectos, a linguagem aqui assume um processo de "ação e interação no mundo" (GERALDI, 2015, p. 384), sendo essencial o desenvolvimento das suas variadas habilidades.

Concordando com as novas perspectivas linguísticas, já em um momento posterior, a língua oral cada vez mais passa a tomar espaço que até então não tinha praticamente nenhuma visibilidade. Dessa maneira, os discursos que se detêm à língua falada, começaram a ganhar mais força no contexto educacional do Brasil após, especialmente a elaboração/execução do Projeto de Estudo da Norma Linguística Urbana Culta no Brasil - NURC ${ }^{2}$. (MENDES, 2005)

Dado o passo inicial para as discussões acerca da modalidade oral da língua, as teorias, mesmo que ainda de forma rasa, começaram a direcionar trabalhos que visavam discutir, principalmente sobre a oralidade e a sua inserção como objeto de ensino nas escolas. Assim, no campo do ensino, os Parâmetros Curriculares Nacionais - PCN (BRASIL, 1998), documento oficial que regula a educação em nosso país é apresentado com um novo propósito, pois traz a obrigatoriedade da inserção da língua oral como objeto de ensino nas aulas de língua materna. Tal fato indica mudanças ${ }^{3}$, sobretudo, nas questões metodológicas dos modos de ensinar e, por conseguinte o que até então vinha sendo negado passa a ganhar seu espaço, sendo esse o período em que, de fato, a língua oral assume o cenário das discussões.

Após a inserção dos PCN (BRASIL, 1998, p. 18), o ensino em vigor passou a ser visto como tradicional, pois os princípios norteadores das práticas, tais como: "a excessiva valorização da gramática normativa", "o consequente preconceito contra as formas de oralidade e as variedades não-padrão", "a desconsideração da realidade dos alunos", dentre outros, passaram a perder espaço (pelo menos teoricamente) para outros propósitos.

Então, é dever da escola "ensinar o aluno a utilizar a linguagem oral no planejamento e realização de apresentações públicas: realização de entrevistas, debates, seminários, apresentações teatrais etc.” (BRASIL, 1998, p. 25). Desse modo, é preocupante pesquisas

\footnotetext{
${ }^{2}$ Esse projeto teve início em 1969, liderado por Ataliba de Castilho, e foi realizado em cinco cidades brasileiras (Recife, Salvador, Rio de Janeiro, São Paulo e Porto Alegre).

${ }^{3}$ Corroboramos com GERALDI (2015) ao destacar que a inserção de novas concepções e práticas devem, sobretudo, levar em consideração "as possibilidades reais que as escolas e os professores têm para concretizar tais mudanças.” Portanto, não apresentamos aqui a conformidade de que todas as transformações (ou tentativas dessas) são a resolução dos impasses referentes ao dinâmico contexto da escola.
} 
demonstrarem que "havia, como ainda hoje é, o predomínio do trabalho com a escrita, a leitura e a gramática”. (BUNZEN, 2017, p. 14)

É nesse ambiente da inserção de novas questões, que se pode destacar também, por exemplo, o cenário do Ensino Médio, período final da Educação Básica, que tem como finalidade assegurar ao aluno a preparação e continuidade dos estudos, para o trabalho e o exercício da cidadania. Diante das tentativas de mudanças, ressaltam-se também as implicações causadas após a implementação das Diretrizes Curriculares Nacionais para o Ensino Médio - DCNEM (2011), que viabilizam uma proposta de ensino-aprendizagem pautada em ações questionadoras sobre as etapas da escolarização.

Nesse contexto, a língua oral também ganha a ideia de uma necessidade de ser efetiva em sala de aula, apresentada em uma passagem na DCNEM (BRASIL, 2011, p. 10) ao destacar que "A língua verbal, oral e escrita, representada pela língua materna, ocupa na área o papel de viabilizar a compreensão e o encontro dos discursos utilizados em diferentes esferas da vida social". (BRASIL, 2011, p. 10) Por tal razão, nos reportamos novamente ao nosso questionamento central, ou seja, acerca da carência do trabalho como a oralidade em sala de aula.

Por que essa tradição ainda está sendo perpetuada? Por que fala e escrita continuam sendo vista como dicotômicas? Mesmo diante das diversas tentativas de mudanças manifestadas é lenta a efetivação de muitas questões porque algumas destas não estão facilmente ao alcance do professor por inúmeros fatores e, além disso, trazem consigo o peso de uma tradição/construção histórica custosa de se romper.

Para entender tais fatos, segundo Marcuschi e Dionisio (2007), se faz necessário procurar entender, em especial, a relação entre escrita e fala, pois dos inúmeros equívocos existentes que envolvem a abordagem da oralidade nos trabalhos realizados nas aulas de Língua Portuguesa estão atrelados, acima de tudo, a ideia errônea que se tem sobre a relação entra ambas as modalidades da língua.

Junto a esse ponto é preciso ressaltar que "fala e escrita constituem duas modalidades de uso da língua. Embora se utilizem, evidentemente, do mesmo sistema linguístico, elas possuem características próprias" (KOCH, 2014, p 77). Mesmo que a língua escrita seja a mais estudada, sabemos que é como língua oral que seu uso passa a ser mais comum no nosso dia a dia. (MARCUSCHI; DIONISIO, 2007)

Nas palavras de Marchuschi (2003), o autor defende uma noção de continnum em que visa desfazer, principalmente a ideia preconceituosa em relação à oralidade, voltando-se para a existência de uma ligação entre os aspectos que envolvem fala e escrita, evidenciando que estes se interpenetram, desmistificando a noção dicotômica entre ambas.

Por isso, defendemos, tal como propõem Koch (2014, p. 81), que "o texto falado não é absolutamente caótico, desestruturado, rudimentar. Ao contrário, ele tem uma estrutura que lhe é própria, ditada pelas circunstâncias sociocognitivas da sua produção e é à luz dela que deve ser descrito e avaliado". Logo, cabe à escola mostrar as variadas situações de uso/níveis - da fala e da escrita - proporcionando aos alunos uma ativa participação nas diferentes esferas sociais. (FÁVERO; ANDRADE; AQUINO, 2012) Desse modo, o ensino da modalidade oral deve ocupar um lugar efetivo nas salas de aula, influenciando diretamente no contexto escolar ao perpassar as diferentes esferas entre professores e alunos.

\section{PERCURSO METODOLÓGICO: UMA DESCRIÇÃO DO CAMINHO TRAÇADO}

Nesta seção, iremos apresentar aspectos relacionados ao contexto da pesquisa, ou seja, detalharemos o corpus escolhido e os procedimentos metodológicos utilizados. Como já citado na parte introdutória deste artigo, esta discussão encontra-se centrada em interlocuções 
feitas acerca do evento $O$ Ceará Científico $^{4}$ - Etapa Regional, uma ação da Coordenadoria Regional de Desenvolvimento da Educação - CREDE 10, que na edição de 2016 unificou a VIII Feira Regional de Ciências e Cultura e a V Mostra Regional de Educação Ambiental da Rede Estadual de Ensino.

Este evento é considerado a organização de maior expoente no que diz respeito aos acontecimentos direcionados para área da educação nos 12 municípios que compõem a CREDE 10. Na etapa regional, acontece uma migração dos projetos selecionados nas diferentes escolas da região, proporcionando um momento destinado para culminância de uma série de trabalhos exitosos realizados ao longo do ano.

Logo, o objetivo do evento é envolver e incentivar as escolas públicas das redes Estadual e Municipal de Ensino Fundamental e Médio, do Estado do Ceará, a apresentarem/discutirem acerca dos trabalhos científicos e culturais desenvolvidos através das Feiras Escolares e Municipais, sendo o Ceará Científico - Etapa Regional a $1^{\text {a }}$ culminância, que posteriormente resulta em uma fase estadual.

Dentro desse contexto, nos detemos aos 12 (doze) projetos classificados na categoria de linguagens apresentados no ano de 2016. A justificativa para o recorte desses trabalhos que compõem o corpus da pesquisa está na sua posição classificatória, tendo em vista que estes foram considerados como os mais relevantes pela comissão avaliadora, bem como por se enquadrarem na área das nossas discussões.

Por esse motivo, é válido destacarmos que as questões oriundas da análise dos projetos selecionados não têm nenhum interesse em apresentar posicionamentos que limitem o caráter positivo dos trabalhos desenvolvidos. Longe disso, reconhecemos a importância do que foi executado e de suas consequências, considerando as múltiplas situações do contexto escolar.

Em se tratando do processo da coleta de dados para a realização desta pesquisa foi feita primeiramente uma leitura e uma análise de cada projeto com o intento de verificarmos se existe uma abordagem da oralidade e, em caso positivo, analisar como ocorre efetivamente esse trabalho. Logo após, parte da análise foi representada por meio de um gráfico ${ }^{5}$, a fim de didaticamente discutir e expor os resultados constatados.

Assim sendo, nossa pesquisa não é de cunho quantitativo, pois não nos interessa saber a quantidade relacionada ao evento, já que para nosso objetivo a designação numérica não é significativa. Voltamo-nos, então, para uma natureza qualitativa que para Minayo (2009) é um modelo de abordagem que busca responder a questões muito particulares e não se preocupa em quantificar a realidade observada. Nesse sentido, a abordagem qualitativa se preocupa em perceber as diferentes nuances do contexto investigado, compreendendo os sentidos atribuídos pelos sujeitos à sua realidade. Já em relação ao procedimento utilizado para a análise dos dados, nos amparamos em Gil (2002) para classificar a pesquisa como bibliográfica, visto que esta é desenvolvida com base em material já elaborado, por exemplo: livros, artigos científicos.

Portanto, adiante iremos refletir sobre as questões propostas, expondo uma ponderação sobre o contexto em que estas se encontram do mesmo modo que apresentamos os resultados dessas reflexões e suas possíveis ligações com a base teórica adotada.

\footnotetext{
${ }^{4}$ Todas as informações referentes ao evento foram retiradas do edital que se encontra disponível para acesso no site: http://www.crede10.seduc.ce.gov.br/index.php/noticias/3154-crede-10-divulga-edital-do-ceara-cientifico2016-etapa-regional.

${ }^{5}$ Embora seja apresentado um gráfico para a demonstração da análise do material utilizado como corpus, nos detemos aos números apenas como meio para representar de forma mais didática as questões encontradas. Desse modo, a natureza da pesquisa é essencialmente qualitativa, uma vez que o propósito é analisar o ensino da oralidade na escola, por meio da interpretação das práticas didáticas desenvolvidas através dos projetos analisados.
} 


\section{DA ANÁLISE DOS PROJETOS: UMA VISÃO SOBRE $O$ QUE É E COMO SE ENSINA A LÍNGUA ORAL}

Não se acredita mais que a função da escola deva concentrar-se apenas no ensino da língua escrita, enfatizando somente a estrutura e o seu vocabulário. A pouca importância dada ao ensino da modalidade oral pelo pretexto de que o aluno já aprendeu a língua falada em casa, impede o desenvolvimento pleno do educando, e a função de prepará-lo e qualificá-lo para o exercício da cidadania. (CASTILHO, 2011, p. 13)

É por essa razão que a discussão apresentada até agora se detêm na tentativa de compreender e analisar o lugar destinado aos aspectos específicos da oralidade nas atividades em sala de aula, acentuando a importância de se trabalhar sistematicamente as suas particularidades, principalmente, por meio dos diversos gêneros textuais orais.

Para tanto, resumindo os projetos analisados e preservando, especialmente, a autoria ${ }^{6}$ das pesquisas, se pode perceber que há uma variação considerável nas propostas de trabalho. De maneira geral, cada estudo expõe um tema central e, a partir deste, explora suas especificidades. Assim, adentrando nesse universo das particularidades de cada projeto foi possível perceber que a escrita, a leitura e a oralidade ocupam lugares e concepções distintas, seja na sua forma de abordagem ou na visão teórica tomada como base.

Sobre essa distinção entre as abordagens, estas podem ser facilmente verificadas conforme nos mostra o gráfico 1 a seguir:

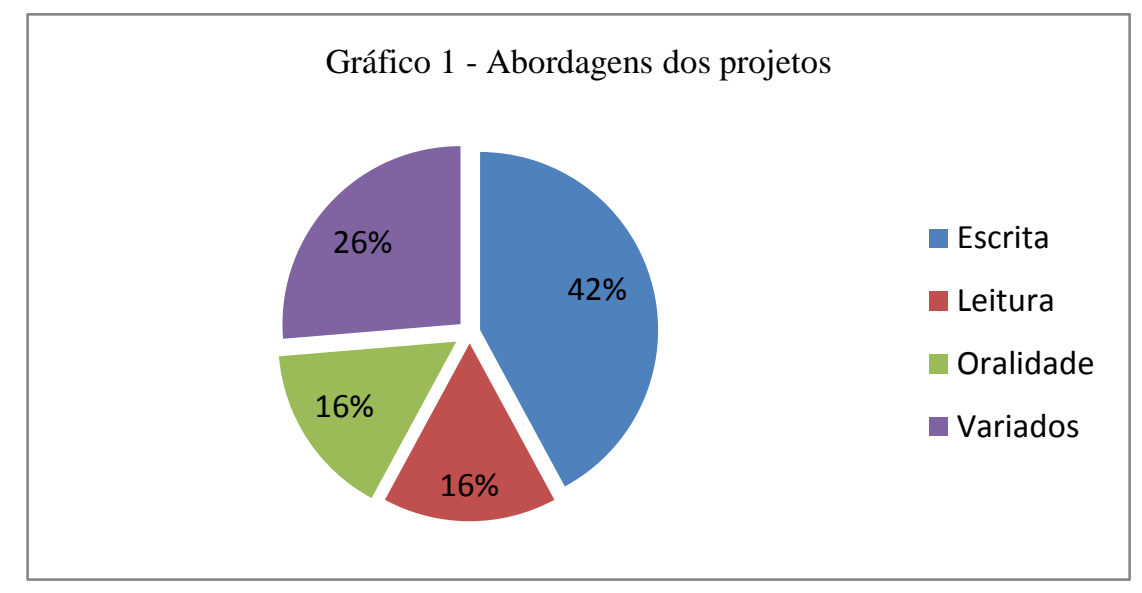

Fonte: elaboração própria

Nesta demonstração acima é manifestada a discrepância entre o foco dos distintos projetos. Como se pode observar, a escrita vem claramente assumindo uma posição de destaque, enquanto a oralidade e a leitura ocupam o mesmo lugar, que se diferenciam moderadamente da categoria dos variados, que foi criada para identificar a abordagem de assuntos que não entram na discussão aqui proposta.

Para que possamos explorar os aspectos trabalhos referentes à modalidade oral, se faz necessário antes entendermos como as categorias - escrita e leitura são abordadas. Logo, destacaremos a maneira como estas aparecem nos projetos e quais as diferenças entre ambas para que seja possível interpretar as práticas relacionadas com a língua oral.

\footnotetext{
${ }^{6}$ A fim de preservar os trabalhos analisados, bem como suas autorias não será exposto o nome dos autores e nem o título de seu projeto, ou seja, todas as informações sobre o material explorado foram identificadas por expressões fictícias, por exemplo: P1 - Projeto 01, P2 - Projeto 02 e, assim, sucessivamente.
} 
A categoria nomeada de escrita é a mais enfatizada nos projetos. Em sua maioria estes trazem nas suas seções posicionamentos demonstrando que a escrita é o foco principal, e, mesmo que isso não esteja presente em todos os trabalhos, nos parece ainda ser essa modalidade sempre um apoio para as variadas atividades desenvolvidas. Prova disso, é que mesmo o projeto trazendo como ponto central a discussão de outras questões, a escrita sempre se faz presente, sendo muitas vezes apresentada com mais prioridade do que mesmo o próprio foco principal do projeto.

Tal questão pode ser observada facilmente nos excertos a seguir, retirados das seções apresentadas no P7 e P8. Vejamos:

(1) "o prazer pela escrita [...] estimular e valorizar a escrita [...] o avanço na escrita [...] incentivando à escrita [...] alunos mais conscientes, críticos, leitores e produtores de textos [...] o crescimento na escrita" (P7) [destaques nossos]

(2) Objetivo geral - Analisar se proporcionando ao educando um trabalho com arte pode resultar numa mudança de atitude dos alunos na disciplina de Língua Portuguesa, na busca de cidadãos mais conscientes, críticos, leitores e produtores de textos, assim como apreciadores de arte. (P8) [destaque nossos]

Os posicionamentos apresentados deixam claro que em um grupo de projetos a escrita é prioritária e, além disso, como já foi supracitado, assume um segundo plano em variadas situações como é o caso do P8 que de modo geral se propõem "a trabalhar a aprendizagem por meio da arte".

Todavia, no objetivo do P8 é possível perceber que está inclusa a produção de textos embora o foco do trabalho seja outro. Diante disso, ao analisarmos inicialmente o objetivo geral não fica claro quais serão os gêneros textuais trabalhados e qual a modalidade da língua. Porém, é visível, com a leitura do restante do projeto, que a produção de textos exigida se detém em específico aos gêneros textuais da modalidade escrita, pois é solicitado, por exemplo, a elaboração de "contos, poemas..." (P8) no decorrer das atividades do projeto.

Tal questão condiz com o posicionamento de Marcuschi e Dionisio (2007, p. 29) quando enfatizaram o equívoco cometido nas práticas escolares ao considerarem "a escrita como um padrão linguístico no qual se define o que é certo e errado, sem atenção para a diversidade da produção textual." Essa concepção parece perpetuar no corpus de nossas investigações, já que a escrita assume um papel primordial nos trabalhos analisados e que se encontra em sua grande maioria como foco central, até mesmo quando não há a suposta intenção de que seja trabalhado as suas especificidades.

Em se tratando da leitura, assim como a oralidade, esta assume uma porcentagem de abordagem bem menor do que a escrita, vejamos o que dizem os projetos:

(3) "Despertar na comunidade escolar o gosto pela leitura, o hábito de ler e o prazer pela escrita, contribuindo assim para um melhor desenvolvimento intelectual, cultural, social e afetivo." (P3) [destaques nossos]

O P3 bem como o grupo de projetos que têm as mesmas características anuncia em seu título e no decorrer de seu conteúdo que se trata de um trabalho cujo objetivo é de dedicar-se às questões relacionadas à leitura. No entanto, ao longo da descrição de suas atividades, a modalidade escrita da língua novamente acaba assumindo uma posição enfática, que por muitas vezes nos parece ser o ponto central das atividades desenvolvidas, fato que não acontece da mesma forma com a língua oral. Logo, pode-se constatar uma abordagem 
semelhante entre escrita e leitura, diferenciando-se apenas na recorrência, pois a escrita permanece predominando nos projetos. Queremos deixar claro que reconhecemos a importância de trabalhar a escrita e defendemos que tanto a escrita quanto a oralidade devem ser ensinadas, sem que, para isso, uma ou outra deixe de ser objeto de ensino.

Já em relação à oralidade, embora seja até citada, em nenhum momento parece ser o cerne das atividades. Isso pode ser facilmente observado nos excertos abaixo:

(4) "Promover troca de experiências e conhecimento entre os participantes do debate." (P7) [destaque nosso]

(5) "Observou-se que após a prática da leitura de jornais e revistas o aluno, mostrou avanço na oralidade, na escrita e nas produções diárias." (P7) [destaque nosso]

(6) "Além disso, possibilitou aos alunos um maior estímulo à leitura e à expressividade oral que esse texto poético requer.” (P4) [destaque nosso]

Nos excertos 4 e 5, é demostrado que o P7 apresenta incialmente uma proposta de trabalho com o gênero textual oral debate. Todavia, não é possível identificar, ao longo das suas seções, que este trabalho é de fato realizado, já que se manifesta uma relação das atividades da língua oral estritamente (e até equivocamente) com as atividades de leitura. Tal questão ainda é reforçada na própria porcentagem demostrada no gráf. 1 apresentado anteriormente, no qual as categorias leitura e oralidade ocupam igualmente um total de $16 \%$ dos projetos analisados, assim, é inegável a estreita relação entre ambas.

Não poderíamos julgar essa relação como um equívoco desde que ambas (leitura e oralidade) estivessem bem delimitadas e as suas especificidades fossem contempladas nos trabalhos. Porém, isso não acontece nos projetos analisados, pois essa delimitação necessária não é exposta; pelo contrário, há, como já referido, uma contradição nos trabalhos. De modo semelhante, o P4 que trata da socialização de trabalhos com cordéis, ressalta a expressividade oral como um trabalho efetivo com a oralidade, quando o que, de fato foi executado trata-se de uma atividade de oralização da escrita.

Ainda nos detendo ao P7, por exemplo, este não apresenta as características do gênero discursivo oral - debate. $\mathrm{O}$ trabalho é efetivado a partir de leituras realizadas pelos alunos e posteriormente estes são postos em um momento de compartilhamento de ideias sem que tenham acesso às particularidades da produção do gênero e da modalidade que faz parte.

Percebemos que a concepção de base dos projetos vem compatível com as colocações de Marcuschi; Dionisio (2007, p. 29) quando ressaltaram, que na visão de alguns matearias didáticos "confunde a análise da oralidade com algumas atividades de oralização da escrita." A partir da análise dos projetos é concebível demonstrar que esse equívoco em alguns casos vai além dos manuais, e encontra-se corriqueiramente presente nas práticas escolares.

Com isso, acentuamos as colocações de Forte-Ferreira (2014, p. 37) quando considera "a oralidade como o desenvolvimento da fala [...] e não a modalidade que prepara para a escrita e muito menos a oralização do escrito [...]", concepção esta que constitui a base teórica norteadora das nossas discussões, sendo a nosso ver uma posição relevante para o embasamento das atividades com a língua oral no contexto escolar.

Em suma, o que se pode perceber de maneira geral é que há uma carência no tocante à modalidade oral em sala de aula, demonstrando uma supremacia da escrita, bem como fica claro um equívoco nas atividades que possivelmente possam intencionar um trabalho com a 
oralidade, já que estas se apresentaram em sua maioria como uma prática de oralização da escrita.

\section{CONSIDERAÇÕES (SEMI) FINAIS}

Conforme foi possível perceber ao longo do estudo de algumas discussões que embasam esse trabalho, a abordagem dos gêneros orais exige o posicionamento teórico e metodológico que considere as nuances da modalidade oral da língua.

Logo, nesta investigação, o nosso propósito foi discutir acerca da oralidade em sala de aula, analisando o espaço que se tem destinado para a língua oral nos projetos científicos desenvolvidos em turmas da rede pública do Estado do Ceará. A partir deste objetivo, investigamos o que é e como se ensinam questões direcionadas para a oralidade na concepção apresentada pelos projetos estudados.

Os resultados da análise dos dados apontaram que a oralidade é vista como práticas variadas de leitura, ou seja, oralização da escrita, além de apresentarem uma supremacia da escrita em detrimento da oralidade. Consequentemente, foi possível constatar um equívoco na maneira como as atividades são conduzidas, uma vez que estas não levam em consideração as especificidades da língua oral.

Por fim, enfatizamos o quanto são essenciais tais reflexões para o ensino de línguas, pois é fundamental preparar o aluno para a produção de gêneros textuais nas modalidades escrita e oral para que ele tenha desenvoltura nas mais diversas práticas interativas das quais participar.

\section{REFERÊNCIAS}

ARAÚJO, Denise Lino de.; SILVA, Williany Miranda. A oralidade em foco: conceitos, descrição e experiências de ensino. 2. ed. Campinas, SP: Pontes Editores, 2016.

BAKHTIN, Mikhail. A interação verbal. In: . Marxismo e filosofia da linguagem. São Paulo: Hucitec, 2006. p. 112-130.

BRASIL. Ministério da Educação. Secretaria de Educação Fundamental. Parâmetros Curriculares Nacionais: Língua Portuguesa. Brasília, 1998.

Ministério da Educação. Secretaria de Educação Fundamental. Diretrizes Curriculares Nacionais para o Ensino Médio. Brasília, 2011.

BUENO, Luzia; COSTA-HUBES, Terezinha da Conceição. (Org.). Gêneros orais no ensino. Campinas, SP: Mercado de Letras, 2015.

CASTILHO, Ataliba Teixeira de. A língua falada no ensino de português. 7. ed. São Paulo: Contexto, 2011.

CUNHA, Angélica Furtado da; COSTA Marcos Antonio ; MARTELOTTA, Mário Eduardo. Linguística. In: Contexto, 2013. p. 15-30. Mário Eduardo. (Org.). Manual de Linguística. 2. ed. São Paulo: 
FÁVERO, Leonor Lopes; ANDRADE, Maria Lúcia C. V. O; AQUINO, Zilda. G. O. Oralidade e escrita: perspectivas para o ensino de língua materna. 8. ed. São Paulo: Cortez, 2012. P.

FORTE-FERREIRA, Elaine Cristina. A oralidade como objeto de ensino: por uma perspectiva de desenvolvimento da língua oral a partir do gênero debate. 2014. 229 f. Tese (Doutorado em Linguística) - Programa de Pós-Graduação em Linguística, Universidade Federal do Ceará - UFC, Fortaleza-CE, 2014.

GERALDI, João Wanderley. O ensino de Língua Portuguesa e Base Nacional Curricular Comum. Revista Retratos da Escola, Brasília, v. 9, n. 17, jul./dez. 2015. p. 381-396.

GIL, Antônio Carlos. Como elaborar projetos de pesquisa. São Paulo: Atlas, 2002.

$\mathrm{KOCH}$, Ingedore Villaça. A natureza da fala. . Ingedore Villaça. $O$ texto $e$ a construção dos sentidos. 10. ed. São Paulo: Contexto, 2014. p. 77-92.

MARCUSCHI, Luiz Antônio. Gêneros textuais: definição e funcionalidade. In: DIONÍSIO, Ângela Paiva; MACHADO, Anna Raquel e BEZERRA, Maria Auxiliadora. (Org.). Gêneros textuais e ensino. Rio de Janeiro: Lucerna, 2003. p. 19-36.

Luiz. Antônio; DIONÍSIO, Ângela Paiva. Princípios gerais para o tratamento das relações entre a fala e a escrita. Fala e escrita. Belo Horizonte: Autêntica, 2007. p. 13-30.

Luis. Antônio. Produção textual, análise de gêneros e compreensão. São Paulo: Parábola Editorial, 2008.

MENDES, Adelma das Neves Nunes Barros. A linguagem oral nos livros didáticos de língua portuguesa do ensino fundamental $3^{\circ}$ e $4^{o}$ ciclos: algumas reflexões. 2005. $199 \mathrm{f}$. Tese (Doutorado em Linguística Aplicada aos Estudos da Linguagem) - Programa de estudos pósgraduados: Linguística aplicada e estudos da linguagem, Pontifícia Universidade Católica de São Paulo, São Paulo, 2005.

MINAYO, Maria Cecília de Souza. C. de S. O Desafio da pesquisa social. In: DESLANDES, Suely Ferreira; GOMES, Romeu, , Maria Cecília de Souza. (Org.). Pesquisa social: teoria, método e criatividade. 23. ed. Petrópolis, RJ: Vozes, 2009. p. 09-29. 